\title{
Implantation of Core Literacy Indexes for Students' Development in the Training of High-end Technical Talents
}

\author{
Jianqing Xiong ${ }^{1}$, Shuli Zhao ${ }^{2}$ and Yingjun $\mathrm{Li}^{3}$ \\ 1,2,3Beijing Agricultural Vocational College 100012
}

Keywords: Development of students' Core Literacy; High-end Technical talents; Through training; Indexes

\begin{abstract}
In September 13th 2016, the Ministry of Education released the results of the research on the development of core literacy of Chinese students, which indicates that the direction of education in China has changed from knowledge to knowledge. Chinese students' development of core literacy is the full manifestation of China's educational reform, the concept of educating people in line with international standards, and the education strategy of the country. In 2015, the Beijing Municipal Education Commission launched a project for the development of high-end technical skills. In order to better organize and implement this project, this paper puts the concept and indicators of students' development of core literacy into the project. To make the training program of the project more optimized, The goal of training is more scientific, and the training of talents is more comprehensive.
\end{abstract}

In 2014, the Ministry of Education developed and issued opinions on comprehensively deepening the curriculum reform and carrying out the fundamental task of creating a person by virtue. The Ministry of Education proposed that "the Ministry of Education will organize research and put forward a core literacy system for the development of students from various stages of learning." It is clear that students should have the necessary character and key abilities to meet the needs of lifelong development and social development ". At that time, Lin Chongde, a senior professor at Beijing normal University, will lead the research team to undertake this major task entrusted by the Ministry of Education. Select and define the core accomplishment of Chinese students' development. In September 13th 2016, the research results of Chinese students' development core literacy were officially released, and "Chinese students' development core literacy" became a teaching in a short period of time. Cultivation and development of students' core accomplishment is the national development strategy. The fundamental starting point is to carry out the Party's educational policy, to practice the socialist core values, and to carry out the fundamental task of building people by virtue. Emphasizing the sense of social responsibility, innovative spirit and practical ability, promoting the all-round development of students and making them qualified builders and reliable successors of socialism with Chinese characteristics in the new era. How to realize the six Core qualities of students' Development in School training goals, Curriculum goals and Educational and Teaching activities, how to transform them into the guiding ideology of Curriculum Reform and into the subject competence Literacy of Teachers It is the most important task of the future school education to cultivate the students' subject accomplishment. It is the innovation in the field of vocational education in Beijing and even in the whole country that the advanced technical and technical talents of Beijing should be carried out through the training project. How to carry out the idea, connotation, target and target of cultivating and developing students' core accomplishment in the project of training high technical skill talents can ensure the good operation of the project. It is also an urgent need to study and think about the goal of cultivating "advanced technical talents" in the course of implementation of this project.

\section{The Connotation of the Cultivation of High-end Technical Talents and the Development of Students' Core Literacy}

Training of High-end Technical Talents. In 2015, Beijing launched a pilot project for the training of advanced technical and technical talents. The project integrates basic education, vocational education and higher education. The training model of the project is "232", that is, junior high 
school graduates receive two years' education in basic cultural courses. Three years of higher vocational education, two years of undergraduate education, that is, seven years of continuous study and a bachelor's degree. The personnel training system of vocational and technical education and higher education. It brings together the high quality teaching resources of famous teachers and enterprises of various schools and colleges and universities. It takes strengthening the scientific foundation and the humanities accomplishment, ramming up the foundation of mathematics, physics, language, history, geography and biology as the main line To carry out general quality education, to improve practical innovation and practical ability as the core, to strengthen technical skills as the focus, to develop and train the vocational ability required by the top industry, and finally to make the students have a solid cultural foundation. First-class professional literacy, skilled professional skills, strong innovation and development of high-end technical skills.

The Training Objectives and Main Tasks of the Education Stage of the Basic Culture Curriculum in the "2" Year. In this stage, students adopt a non-professional approach to complete the basic courses in basic education, such as learning, mathematics, science, chemistry, English, humanities and so on. The basic culture curriculum integrates the high school curriculum system of high quality, and develops general education and pre-university courses. Cultivate and practice the socialist core values, enhance students' humanistic, scientific and health literacy, enhance students' innovative spirit, practical ability and social responsibility, To cultivate students' ability of international communication and sustainable development, to carry out quality-oriented education in an all-round way, to select teaching contents and to optimize teaching organization and methods, so as to lay the foundation for linking up the latter two stages of education. This stage is carried out by Beijing Agricultural Vocational Science. The college and Beijing 12 cooperate deeply, fully absorb 12 middle school education idea, teaching resources, teaching method organize teaching, hire foreign teachers to participate in English teaching, improve English application and communication ability.

The Training Objectives and Main Tasks of the "3" Year Specialized Curriculum and the Stage of Vocational Skill Education. After completing the study of basic education for two years, we can turn to the stage of higher vocational education to study and master the basic professional knowledge, basic technical theory and professional core skills. So that students have higher vocational skills, stronger practical ability, can solve problems creatively, pay attention to the study of linking up with undergraduate course, and prepare for the next stage of undergraduate major study.

The method of turning a section is that the college unifies the organization of the transition examination, and the students who pass the examination are promoted to the next stage. The choice of major can be taken by the students voluntarily, or they can be divided according to the academic results of the previous two years and the grades of the transition examinations. Fully considering the students' personality choices, after three months of trial study, they can also apply for a change of major according to the regulations. Professional education courses aim at the demand for talents in the top-notch industries, and through cooperation with the first-class universities and scientific research institutes in the country, Cooperation and training of large enterprises at home and abroad, together to develop talent training programs and plans, training international, high level, innovative, composite talent.

The Training Objectives and Main Tasks of Undergraduate Major Education Stage in "2" Year. Students who have completed their studies in higher vocational education and who have passed the examination for the transition to higher vocational education may enter the undergraduate stage of their studies. In this stage, it is necessary to further deepen the professional theoretical study and carry out the measures for managing the student status of undergraduate institutions in grades .6 to 7. Those who have completed the academic tasks of two academic years, have obtained the graduation certificate at the undergraduate level of general higher education, and have met the requirements of the bachelor's degree in their colleges and universities, shall award the bachelor's degree. Strengthen the cultivation of technical research ability, innovation ability and technical application ability. 
Students' Development of Core Literacy. The core accomplishment of student development mainly refers to the essential character and key ability that students should possess and can adapt to the needs of lifelong development and social development. The core is to cultivate "all-round development person", which is divided into cultural foundation and independent development. Social participation in three aspects. The comprehensive performance of the humanities, scientific spirit, learning to learn, healthy life, responsibility, practice and innovation six great qualities, The core accomplishment is a comprehensive expression of students' knowledge, skills, emotions, attitudes, values, etc. It is the success of each student in life. Adapt to individual lifetime development and social development The cultivation of students' core literacy is a continuous lifelong process, which fully embodies the basic characteristics and principles of science, times and nationality.

Culture Base. The emphasis is on the ability to acquire knowledge and skills in the humanities, science and other fields, to master and apply the outstanding achievements of human wisdom, to preserve the inner spirit, and to pursue the unity of truth, good and beauty. To develop into a generous cultural foundation, a higher spiritual pursuit of the people.

Independent development. Including learning to study and living healthily. Emphasis is placed on being able to manage one's own study and life effectively, to recognize and discover self-worth, to discover one's own potential, to cope effectively with the complex and changeable environment, and to achieve great success in life. Develop into a person with a clear life direction and a quality of life.

Social Participation. The emphasis is on how to deal well with the relationship between oneself and society, to develop the moral norms and codes of conduct that modern citizens must abide by and fulfill, and to enhance the sense of social responsibility. Promote the spirit of innovation and practical ability, promote the realization of personal value, promote social development and progress, develop into people who have ideals and beliefs, dare to bear.

\section{The Present Situation of the Study on the Above Two Problems at Home and Abroad}

The Origin and present situation of Core Literacy Research abroad. As early as 20th century, major developed countries and international organizations such as the OECD, the European Union, the United Nations Educational, Scientific and Cultural Organization, and other international organizations, in order to further enhance their competitive strength and enhance the quality of talent training, The United Kingdom is the first country to put forward the concept of core literacy, which has been widely concerned and mentioned in the field of social science research in western countries such as Europe and the United States. In 1997, the Organisation for Economic Cooperation and Development (OECD) launched the "definition and selection of Literacy" transnational research project, proposing "people and tools", "people and themselves". ",", "people and society" three aspects of the core literacy framework. The European Union will develop core literacy into "lifelong learning core literacy," and believe: lifelong core literacy can achieve self-development, integration into society and competence as the purpose, The need for a variety of skills, knowledge, and attitudes. Although there are different expressions for "core literacy" in different countries. In 21th century, the United States called it "skills 21th century," the Organisation for Economic Cooperation and Development called it "key Literacy," and Australia referred to it as "Comprehensive." "ability". But they all express different organizations, Countries and regions should cultivate education How to raise the quality of the exploration and attention.

Research and Application of students' Core Literacy in China. In 2014, according to the spirit of "opinions on comprehensively deepening the curriculum reform and implementing the fundamental task of creating people by virtue", The Ministry of Education has proposed to take the core literacy system of students as a major issue for in-depth study. At that time, Lin Chongde, a senior professor at Beijing normal University, will undertake this major commissioned project by the Ministry of Education. It is understood that, The research group brought together nearly 100 researchers from a number of universities in China. The research group conducted educational policy research, policy research, basic theoretical research, international comparative research, 
traditional culture research, current curriculum standard research, empirical research, etc. 608 representative respondents from 12 sectors were interviewed through the A questionnaire survey was conducted among 566 experts, scholars, principals and entrepreneurs, which formed a record of about 3.51 million words of interviews and a large number of survey data, and solicited opinions and suggestions from all sides in all directions and at various levels. After being examined by the expert working Committee of the Ministry of Education on basic Education Curriculum textbooks, on September 13th 2016, the results of the research on the development of core literacy of Chinese students were officially released. However, how did the research result translate into the guiding ideology of the curriculum reform? It is also a new subject, which needs to be studied and carried out by colleges and universities.

Research on the Cultivation of High-end Technical Talents at Home and Abroad. The opinions of the Ministry of Education on pushing forward the Reform and Innovation of higher Vocational Education and leading the Development of Vocational Education Science (No. 12 of Teaching position [2011]) point out: "higher vocational education aims to cultivate production, construction and service," Management of the first line of high-end technical expertise for the main task.

In 2015, the pilot project was just launched in Beijing for the training of high-end technical and skilled personnel. There are three categories of the project. At present, 12 colleges and universities are serving as experimental schools, with up to 55 professional directions for recruiting students from experimental schools. All of them are aimed at high-end industries in the capital. In addition, it is closely connected with the need of talents for the industrial transformation and upgrading of the capital, and enhances the contribution and influence of vocational education to the economic and social development of the capital, which is related to the highly sophisticated industries that will be vigorously developed in the capital in the next five years. Contribute to the economic and social development and industrial transformation and upgrading of the capital. At present, there are three college students, there are vocational colleges and secondary vocational colleges two modes of training, among which vocational colleges adopt Taking the "232" training model and the "312" training mode of the secondary school as the training model, the project runs through the three stages of high school education, higher vocational education and undergraduate education, and crosses the boundaries of three types of education: basic education, vocational education and general higher education. Through training is an important measure to fully implement the national decision to speed up the modern vocational education. It is a new attempt to explore the mode of high quality and high efficiency vocational education, and it is a high orientation of talent demand for industrial transformation and upgrading in the capital. It is of special significance not only in the history of vocational education in China, but also in the history of reform in the field of education in China. The experimental school is in the stage of research, pilot and perfection, whether it is teaching goal, teaching model, curriculum system, talent training program.

\section{The Purpose and Significance of Implanting the Indicators of Students' Core Literacy into the Penetrating Project}

It is a national development strategy to cultivate and develop the six core qualities of students. The basic starting point is to carry out the Party's educational policy, to practice the socialist core values, to carry out the fundamental task of building up people by virtue, and to stress the sense of social responsibility. Innovative spirit and practical ability to promote the all-round development of students and make them become qualified constructors and reliable successors of socialism with Chinese characteristics in the new era. The training goal, training plan, training idea and student management idea of the advanced technical skill talents can be carried out one by one to form the high-end technology and technology. Can students develop core literacy training project target, curriculum system, academic evaluation system. To promote the educational reform to develop core literacy of students based on the occupation education training not only make some knowledge, skills, abilities, and point to people's spirit, thoughts and feelings, thinking style and value 
formation and promotion, efforts to cultivate students become rich professional knowledge, skilled occupation, profound scientific literacy, physical and mental health of the character, the value orientation of noble occupation talent and industry leading talent cultivation "to achieve all-round development of people" Ban Xuezong purpose.

The Combination of the Two has Improved the Personnel Training Program of the Project. The technical skills of personnel through training goal is to cultivate high-end culture has a solid foundation, first-class occupation quality, professional skills, innovation and development of high-end technical skills talent ability strong, attention is paid to the cultivation of professional skills and occupation ability. And the core of literacy, obviously technology literacy, social responsibility, self-development is the absence, it is the weakness Chinese education. This topic will students develop core literacy index into them and establish a more scientific, comply with the requirements of the times, meet the training objectives of the development needs of the industry of the students' all-round development talents.

The current talent training programs place too much emphasis on teaching and learning of knowledge and skills in disciplines, and the training concept of vocational colleges is also based on professional skills and professional standards, and the model of academic evaluation is also focused on professional skills. Therefore, whether in the talent training plan, teaching concept, teaching mode, academic evaluation, there is a neglect of the core of "cultivate all-round development of the person". This topic will integrate the core quality of student development into the curriculum system, Introduction of academic evaluation system, implantation of the whole process of teaching cultivation, fully reflect people-oriented, all-round development as the core, high value orientation, healthy and happy life and other core qualities.

The Combination of the Two has Further Innovated the Training Concept of the Through-through Project. In theory, to solve the parallel or parallel relationship between students' core accomplishment and subject accomplishment, that is, to make students develop core accomplishment in the stage of vocational education can be carried out. It is also beneficial to embody the unique characteristics and value of professional education. Let students develop their core literacy in the high-end technical skills personnel training project training objectives, curriculum system, teaching process, student management, Academic evaluation and other aspects can be fully reflected and implemented.

Conceptually, whether it is the setting of the training goal, the design of the training plan, the implementation of the training process, or the evaluation system, the students are regarded as the complete living individual, and they pay attention to the essential qualities and core abilities needed for the individual growth. This paper attempts to achieve the all-round development of students through the synergy of various disciplines.

In practice, we have formed the core literacy oriented high-end technical skills personnel through the cultivation of the project student development core literacy index system, curriculum system and academic evaluation system. After the college practice test, It can be implemented and popularized in the training of talents in higher vocational colleges.

\section{Putting Core Literacy into the Project of Cultivation}

Fully Embody the Aim of Developing Students' Core Literacy in the Orientation of Training Goals. China students develop core literacy including cultural foundation, independent development, social participation in three aspects, comprehensive performance for cultural heritage, scientific spirit, learning, healthy life, responsibility, practice and innovation of 6 literacy, specific divided into 18 basic points of national identity. In this paper, the connotation of literacy to each carefully analysis of the specific, systematic, and with high technical skills talents through the characteristics of the project, the training purpose, goal of full integration, will be able to fully embody the characteristics of occupation education, to adapt to the characteristics of modern vocational education, conform to the goal of cultivating high-end technical skills of personnel of accomplishment one by one Then, the research determines the high-end technical skills personnel through the development of core literacy indicators. 
Fully Integrate the Connotation of Students' Core Literacy into the Construction of Curriculum System. The established core literacy will be carried out one by one in the talent training program, and then run through the various stages of learning and be integrated into various disciplines, so that the curriculum content reflects the core literacy, the curriculum structure reflects the literacy structure, and the curriculum quality affects the core literacy. To develop a set of advanced technical and technical talents training scheme which embodies the core quality of students, and to establish a curriculum system oriented by core accomplishment.

Developing students' Core Literacy Idea Through the Whole Process of Talent Training. In the aspects of teaching idea, teaching mode, teaching method and so on, it should be guided by the cultivation of students' core accomplishment, deepen, refine and transform into specific character and ability requirements in the course of teaching, and finally be embodied in the students' body. To expand the ways to develop students' core literacy and improve the effectiveness of cultivating students' core literacy.

On the academic Evaluation system, it is Necessary to Carry out the Guidance of Students' Development Core Literacy in an All-round Way. Focusing on the proposition of developing students' core accomplishment, this paper constructs a student-oriented green evaluation system. It emphasizes on the cultivation of students' professional ability as the core, and on the basis of professional competence and professional standards, from the perspective of knowledge and skills. Ability and quality are used to set the evaluation standard, and the relationships between knowledge and ability, ability and accomplishment, commonness and individuality, apparent quality and potential are handled well, and the examination of students' practical innovation ability of technical skills is highlighted. It emphasizes the examination of students' ability of combining theory with practice, their critical questioning and problem-solving ability, as well as the examination of the development potential of students' comprehensive quality other than knowledge.

To Abide by the Goal of Developing Students' Core Literacy in All-round way in the Quality Education of Students. There is similar to the comprehensive quality of students and quality education in content, there are also some differences. The quality education is the macro guidance of ideological education, cultivating the all-round development of people, profound answer to the education should cultivate what kind of person ". While the core literacy is a specific description of the connotation of quality education, with more guidance and operability, the interpretation of the students should have what kind of character and ability, comprehensive education should be answered:" how to train people ". Therefore, the idea of quality education must be in the crown to the comprehensive quality index, promote the full implementation of quality education, promote core competence indicators of general practice. One is to students community Student associations are important carriers and platforms for cultivating students' in terests, hobbies and specialties, and enrich students' after-school cultural life. To guide student group organizations to develop on a healthy and correct track. Schools should make full use of their spare time, plan, aim, and organize their amateur cultural life, proportion basketball, badminton, billiards, reading, choir, Dance and other community activities. At the same time, give full play to the leading role of the school league branch, class committee, student union, let students self-management, self-service, self-development. Second, based on the social comprehensive practice as the platform to enhance students' cognitive ability. Practice is a comprehensive learning activity, a link between school and society, and a platform between school and society. Therefore, the school should actively organize students to participate in social practice activities, such as volunteer service, community volunteer, professional investigation, industry development research, etc. Improve students' ability of social practice in an all-round way.

\section{Summary}

The development of students' core literacy is the full manifestation of China's educational reform and the concept of educating people in line with international standards. It indicates that the direction of education in China has shifted from the focus on knowledge and skills to the focus on "people-oriented". It is a national education strategy. It is the concrete of educational policy, the 
glue of educational idea, training goal and teaching practice in our country. It is the main idea of guiding all kinds of schools, teaching reform and curriculum reform. How to fully implement the core quality of students' development in all stages of learning is of great importance, and there is a long way to go. This time, we have implanted the core quality indicators of students' development in the course of training, which is also an exploration. It is hoped that the three dimensions, six cores and eighteen basic points of the students' development of the core qualities can be fully implanted in the implementation process of the through-train project, take root, germinate, and blossom and bear fruit. We will strive to make the training plan of the through-through project more optimized. The goal of training is more scientific, and the training of talents is more comprehensive.

\section{References}

[1] Zhao Shuli, Gao Shiji, Li Yingjun, etc. Analysis of Run-through Education Project of Beijing Advanced Technical and Skilled Talents [J]. Journal of Beijing Vocational College, 2017,31 (2):91-94

[2] Xia Fei. Exploration on the Construction of Students' Literacy Education System of the Advanced Technical and Skilled Talents in Run-through Cultivation Basic Stage [J]. Journal of Beijing College of Finance and Commerce, 2016, 32 (3): 34-38

[3] Sun Siyu. Literature Review of Domestic Research on Key Competence.[J]. Elementary Education Studies, 2016 (17): 14-16, 20.

[4] Liang Jiafeng. "2-3-2" Reflections and Practice on Run-through Advanced Technical and Skilled Talents Education. [J]. Beijing Education (Higher Education)

[5] Liu Fang ect. Exploration and Practice of Undergraduate Level Quality Personnel through Vocational Colleges and Universities Segment Training. [J]. Weifang Higher Vocational Education, 2017 (4): 21-25

[6] Wu Yugui. Introduction to Psychology. Beijing Normal University Publishing House, 1991. 